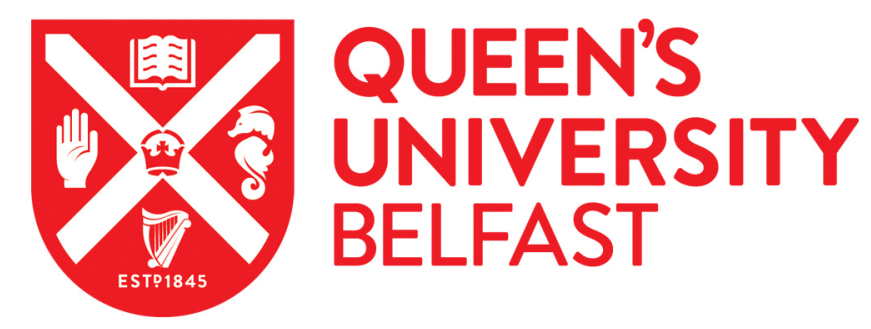

\title{
Bereavement After Informal Caregiving: Assessing Mental Health Burden Using Linked Population Data
}

Moriarty, J., Maguire, A., O'Reilly, D., \& McCann, M. (2015). Bereavement After Informal Caregiving: Assessing Mental Health Burden Using Linked Population Data. American Journal of Public Health, 105(8), 1630-1637. https://doi.org/10.2105/AJPH.2015.302597

Published in:

American Journal of Public Health

Document Version:

Peer reviewed version

Queen's University Belfast - Research Portal:

Link to publication record in Queen's University Belfast Research Portal

Publisher rights

(C) 2013 American Public Health Association

\section{General rights}

Copyright for the publications made accessible via the Queen's University Belfast Research Portal is retained by the author(s) and / or other copyright owners and it is a condition of accessing these publications that users recognise and abide by the legal requirements associated with these rights.

Take down policy

The Research Portal is Queen's institutional repository that provides access to Queen's research output. Every effort has been made to ensure that content in the Research Portal does not infringe any person's rights, or applicable UK laws. If you discover content in the Research Portal that you believe breaches copyright or violates any law, please contact openaccess@qub.ac.uk. 
Title: Bereavement Following Informal Care-Giving: Assessing Mental Health Burden using Linked Population Data ${ }^{1}$

John Moriarty, Aideen Maguire, Dermot O’Reilly and Mark McCann

\section{Objectives}

Unpaid carers who provide intimate support to family members within their home carry out an emotionally intensive role. The health consequences of this undertaking may outlast the life of the family member being cared for, should that care recipient pass away. As part of a large study of mental health outcomes following bereavement, we compared the mental health risk to unpaid carers bereaved of a care recipient with the risk to persons otherwise bereaved and to non-bereaved carers.

\section{Methods}

Prescription records for antidepressant and anxiolytic drugs were linked to characteristics of and life event data of members of the Northern Ireland Longitudinal Study $(\mathrm{N}=317,264)$. We conducted case control analysis, using logistic regression models, stratified by age, to model relative likelihood of mental health problems, using the proxy measures of MH-related prescription.

\section{Results}

Both carers and bereaved individuals were estimated to be at between 20-50\% greater risk of mental health problems than non-carers in similar circumstances (odds ratios for bereaved working age carers: 1.41 ; CI, 1.27-1.57). For older people, there is no evidence of additional

\footnotetext{
${ }^{1}$ The help provided by the staff of the Northern Ireland Longitudinal Study (NILS) and the NILS Research Support Unit is acknowledged. The NILS is funded by the Health and Social Care Research and Development Division of the Public Health Agency (HSC R\&D Division) and NISRA. The NILS-RSU is funded by the ESRC and the Northern Ireland Government. The authors alone are responsible for the interpretation of the data and any views or opinions presented are solely those of the author and do not necessarily represent those of NISRA/NILS.
} 
risk to bereaved carers, though there is for working age people. Older people appeared to recover more quickly from carer bereavement.

\section{Conclusions}

Carers were at risk of mental ill-health during periods providing care and following the death of the cared-for individual. Targeted carer support needs to extend beyond the life of the cared-for individual. 


\section{INTRODUCTION}

Though experiencing bereavement is difficult for any person, some people are affected more acutely $^{1,2}$. It is important to try to understand who will suffer the most after the death of someone close to them, as this can help ensure that available resources reach those bereaved persons in most need of structured support.

The issue of mental health is highly pertinent for those individuals providing unpaid care to members of their family and household with illness or disability ${ }^{3-5}$. Caring workload has been shown to relate to psychological distress among unpaid carers, particularly among those with a high caring burden ${ }^{6}$ and particularly among women ${ }^{4}$. Conversely, however, while health problems have been shown among carers, the caring role has also been shown to predict greater longevity of life ${ }^{5}$. This suggests the existence of benefits underrepresented in the literature, such as increased resilience and personal fortitude.

There are several reasons to believe that bereavement of someone to whom a person has provided care may affect a person differently from bereavement in other circumstances. On one hand, the caring relationship may represent one of greater intensity which is grieved for more profoundly than other bereavement. Attenuated distress may also reflect internalised guilt or continued rumination on the part of the former carer ${ }^{6}$, who may feel their care was insufficient to avert the death, or to improve the person's end-of-life experience. On the other hand, it is argued elsewhere that those who struggle acutely to cope are the minority and that caregivers usually have great resilience from which to draw when the time to comes to grieve for the person they cared for ${ }^{7}$. Furthermore, a study of persons bereaved through cancer revealed that greater duration spent caring for the deceased mitigated against the onset of complicated grief ${ }^{8}$. 
The degree to which either the stresses or benefits associated with caring are accentuated or eliminated by the death of the care recipient has been explored but not firmly established.

While it seems likely that a bereaved carer will grieve differently to other bereaved parties, it is unclear precisely how caring history might modify the mental health burden of bereavement. Beery and colleagues ${ }^{9}$ found those with greater caregiving burdens prior to bereavement to be more likely to experience poor mental health. Bodnar and Kiecolt-Glaser ${ }^{6}$ found no difference between current caregivers' levels of depression and anxiety compared with those bereaved over three years ago, with both groups at elevated risk compared with controls. However, taking a longer observation period, $\mathrm{Hirst}^{4}$ found that caregivers returned to normal levels of psychological wellbeing within five years of the cessation of their role. It is noteworthy that the latter study does not differentiate role cessation through bereavement from other circumstances of cessation, effectively assuming bereavement to be equivalent to a reprieve of caring duty.

Among bereaved caregivers, sociodemographic factors and pre-event mental ill-health have been shown to dispose a person to complicated grief ${ }^{7}$. The growing number of children and young people involved in caring has become an issue of concern to public health communities. Young people are perceived as particularly vulnerable to caring burdens, as well as to interruption of the normative pathway to adulthood via education ${ }^{1,2}$. Furthermore, some authors suggest a differential impact on women because caring roles are placed within a wider portfolio of caring duties, such as childcare, which are borne disproportionately by women ${ }^{3}$. These concerns highlight the imperative to consider which carers will be most affected following bereavement. A further area of interest is the relationship between duration or intensity of the caring period and mental health sequelae. Fujisawa and colleagues ${ }^{10}$ found no additional risk conferred by having being primary carer to the deceased. However, intensity of relationship prior to bereavement (i.e. seeing the person 
every day in their last week of life) did increase the likelihood of complicated grief.

Understanding the relationship between the amount of care given and mental health outcomes post-bereavement would help greatly to disentangle the significance of ending the caring relationship in this way and suggest mechanisms by which this particular type of bereavement will affect mental health.

Conclusions on these questions have usually been drawn from data provided by bereaved individuals accessed through purposive recruiting. This creates two limitations, namely that there is no non-bereaved control group and that willing participants may be an unrepresentative sample of the target population. However, using administrative data from a representative population sample is an unobtrusive alternative in the pursuit of generalizable findings.

\section{Hypotheses}

Given the evidence on either side, the current study adopts two two-tailed hypotheses, namely that the risk of poor mental health outcomes is different for carers who are bereaved compared with:

- non-carers who are bereaved (H1);

- carers who are not bereaved (H2).

If bereaved carers are particularly at risk of, or protected from, poor mental health, we expect that those carers who provided more care would be further at risk or further protected (H3).

\section{METHODS}

\section{Data Sources and Linkage}

This study capitalises on a unique linked dataset which allows for population-wide assessment of mental health outcomes. The spine of the dataset is the Northern Ireland 
Longitudinal Study (NILS). This database contains data from c.28\% of the population of Northern Ireland $(\mathrm{N}=445,819)$ randomly selected by birthdate. NILS comprises administrative healthcare data for this sample linked to the 2001 UK Census $^{2}$ (excluding students not normally resident at the census household). For this project, three additional linkages took place: 1.) death of a co-resident and the cause of death from the General Registrar's Office Death register via the Northern Ireland Mortality Study (NIMS, 20012009); 2.) characteristics of co-residents (e.g. Limiting Long Term Illness) from 2001 Census returns; 3.) records of prescriptions for antidepressant and anxiolytic medication from the Enhance Prescribing Database for Northern Ireland. Accurate electronic prescription records are available for collected scripts from January 2009 forward. Furthermore, an anonymised indicator of prescribing General Practitioner (GP) was included so that practice-level variation in prescribing habits and preferences are not allowed to affect overall estimates of the risk of mental health problems. The current analysis uses as outcome antidepressant or anxiolytic prescription in between January and February of 2010, allowing for all available deaths of participants' census co-residents to be included. Datasets were linked using anonymous one-way encryption methods by the data custodians, and the anonymous data extract was made available to the research team.

For the purpose of the current study, the sample excluded persons aged 6 or younger on Census day $2001(\mathrm{~N}=41913)$ and persons living alone $(\mathrm{N}=47,232)$. Therefore, all study participants were either aged 16 years or turning 16 in 2010 and therefore could experience the outcome as measured. All study participants had at least 1 coresident on Census 2001, allowing for observation of bereavement exposure and caregiving status. We excluded from all analyses cohort members who died $(\mathrm{N}=2478)$ or emigrated $(\mathrm{N}=6976)$ before the period of outcome observation between Census 2001 and the end of 2009 because they could not

\footnotetext{
${ }^{2}$ Subsequent to design and approval of this study, Census 2011 data have been linked to NILS cohort members
} 
experience the outcome of interest in January 2010. We also excluded persons living in a communal establishment $(\mathrm{N}=3643)$ because it was not possible to establish relationships for nonresident family members. In 26,322 cases, it was not possible to match NILS members to the Enhanced Prescribing Database. The remaining study sample consisted of 317,264 individuals.

"Do you look after, or give any help or support to family members, friends, neighbours or others because of:

- long-term physical or mental ill-health or disability

- problems related to old age?

Do not count anything you do as part of your paid employment"

(Response options: None; 1-19 hours a week; 20-49 hours a week; 50+ hours a week)

"Do you have any long-term illness, health problem or disability which limits your daily activities or the work you can do?

Include problems which are due to old age"

(Response options: Yes/No)

If the NILS member reported being a carer in 2001, and one of their co-residents reported having a long-term limiting illness (LLTI) in the same year, the NILS member is assumed to be providing care within the home to that co-resident. If the same co-resident with LLTI in 2001 dies within the lifetime of the study, the person is identified as a bereaved carer. To examine the interaction between carer workload and bereavement, a further set of exposure sub-categories were generated for carers and bereaved carers, namely persons who gave provided care for $0-20 ; 20-50$; or greater than 50 hours per week. 
Four discrete exposure categories were identified: those bereaved of a cared-for co-resident $(\mathrm{N}=5,414)$; carers not bereaved $(\mathrm{N}=18,690)$; other persons (non-carers) bereaved of a coresident $(\mathrm{N}=18,407)$; and the reference group with no exposure to either bereavement or caring burden $(\mathrm{N}=274,753)$.

\section{Analysis}

A case-control analysis of mental health outcomes between January and February 2010 was conducted, controlling for confounders related to the likelihood of both bereavement and mental health problems. These included being female, being older, lower educational attainment and area-level deprivation. Table 1 outlines the distribution of the selected confounders by caring status.

Preliminary analyses tested for moderating influences of gender and age on the relationship between caring status, bereavement and mental health. There was evidence of a significant interaction between age and exposure, with caring roles creating greater risk to mental health for people in emerging adulthood than for older people. There was no evidence of variation comparing males and females. Given these preliminary interactions, predictive models were stratified by age group: young/emerging adulthood age (16-24), working age (25-64) and retirement age (65 and older).

The main logistic regression models used as outcome a binary variable: prescribed antidepressant in either January or February of 2010. Models were robust to the use of two alternative proxy outcome, anxiolytic prescription and length of prescription (available on request).

Given the debate in the literature as to how long subsequent to bereavement a carer might be expected to suffer mental ill-health, two iterations of the main models were produced. The first model restricted bereavement to instances three years or longer prior to the observation 
(December 2006 or earlier), while the second restricted to five years or longer prior (December 2004 or earlier).

\section{RESULTS}

People in the oldest of the three age groups were most likely to be carers, bereaved or nonbereaved, or to be otherwise bereaved, while persons in the youngest group were least likely to experience these exposure conditions $\left(\chi^{2}\right.$ probability $<0.001$ in each case; see Table 1$)$. Among the oldest group, $4.39 \%$ of people had been bereaved of someone to whom they provided unpaid care $(\mathrm{N}=2,491)$, compared with $1.49 \%$ in the working age group $(\mathrm{N}=$ $2,960)$ and $0.17 \%$ in the youngest group $(\mathrm{N}=101)$.

Taking the entire population together, Table 2 shows that risk of poor mental health was greater in each of the three exposure groups when compared to the general population ${ }^{3}$. In descriptive terms, prevalence of antidepressant prescription was highest among bereaved carers, while both non-bereaved carers and bereaved non-carers were more often prescribed to than the reference group $\left(\chi^{2}(3)>1000 ; \mathrm{p}<0.001\right)$.

Unadjusted logistic regression shows overlapping confidence intervals around odds ratios for the two carer categories. While this suggests little evidence for any difference between bereaved and non-bereaved carers, there is evidence that both of these groups are at greater risk of poor mental health than people bereaved in other circumstances of an ill co-resident.

Risk to non-bereaved carers compared with the reference category is evidenced across all age bands, but is particularly acute among young people (Table 2). By contrast, carers of retirement age have only marginally elevated risk of antidepressant prescription. There is also age variation in the effect of bereavement on non-carers. Working age people in this group

\footnotetext{
${ }^{3}$ The discrete proxy outcome referred to is "received/did not receive any antidepressant prescription from January - February 2010". Ordinal logistic models demonstrated that findings were robust to the use of an alternative 6-category outcome.
} 
appear to be less affected by bereavement than persons at either extreme of the age spectrum, though this difference is less pronounced in covariate-adjusted models (Table 3).

\section{Comparing bereaved carers with other bereaved persons}

Among working age people, bereaved carers were around 50 per cent more likely to be prescribed antidepressants than the reference group (Table 2). Bereaved non-carers were also at an elevated risk, but less so than bereaved carers (circa 15\%). The gap between the two narrows in covariate-adjusted models (Table 3). For those bereaved in the past three years, the risk estimated for bereaved carers was larger in descriptive terms, although confidence intervals around the two estimates overlap to a small extent. Furthermore, sub-comparisons by recency of bereavement suggest that the grief trajectory of the two groups differs substantially. The estimated risk to carers bereaved over five years previously differed little from the risk to persons bereaved in the past three years. Working-age noncaregivers who were bereaved before 2005 had a lower risk of receiving antidepressants, suggesting that bereavement effects may be more long-lasting for those who provided unpaid care.

In the retirement age band, antidepressant prescription is initially estimated to be marginally less likely in the bereaved carer group than in the otherwise bereaved group (Table 2). After adjustment for covariates, the risk estimate for both groups is approximately equivalent (38\%; 42\%; Table 3). As with the working age group, the time profiles of the bereavement effect are distinct. For bereaved carers, risk estimates decline steadily with greater length of time elapsed since bereavement, to the extent of being at the margins of significance for those bereaved of a care recipient 5 or more years earlier. Although estimates also fall for bereaved non-carers, the decline is less pronounced.

For the younger age group, while an elevated risk burden is observed for recently bereaved young carers, overlapping confidence intervals suggest that there is little overall difference 
between bereavement effects for non-carers and carers in the young bereaved population. The small sample size means that these comparisons may be underpowered, and prohibits analysis of time since bereavement,

\section{Comparing bereaved and non-bereaved carers}

Among the retirement age band, both bereaved carers and non-bereaved carers were more likely to receive antidepressant prescriptions than the reference group. This is shown in both unadjusted (Table 2) and covariate-adjusted models (Table 3). In descriptive terms, risk estimates are higher for older carers bereaved in the past five years. However, though confidence intervals around estimates for 2007 bereavements suggest a return to the prebereavement levels of relative risk.

For working age people, unadjusted models indicate that bereaved carers were no more likely than non-bereaved carers to be prescribed antidepressants (Table 2). This suggests working age carers are similarly likely to be prescribed for poor mental health regardless of whether or not the care recipient is deceased. Note that adjustment for covariates causes a diminution in the risk estimate for non-bereaved working age carers (Table 3). Comparisons here suggest that recently bereaved carers were at elevated risk of poor mental health.

For young people, although there is clearer evidence of a risk to current caregivers than bereaved carers, estimates for the bereaved are based on small numbers. In and of itself, the substantially elevated risk to non-bereaved young carers, who were at almost twice the risk of poor mental health as non-bereaved non carers is noteworthy, as it suggests that young carers are particularly vulnerable to the mental health burden.

\section{Levels of carer involvement}

There is evidence to suggest that among working age people, people who become bereaved after giving in excess of 50 hours of care per week to the decedent are particularly at risk of 
being prescribed antidepressant medication. Table 4 shows that, among the bereaved carer group, while confidence intervals around risk estimates overlap, risk is clearly elevated for the 50+ hour group when compared to either bereaved non-carers or to non-bereaved carers at the equivalent level of weekly involvement. No corresponding pattern could be determined for persons in the retirement age band. All bereaved carers were at an equivalent level of risk to bereaved non-carers.

\section{DISCUSSION}

Hypothesis 1, that bereaved carers will experience different post-bereavement outcomes from the rest of the bereaved population, is not supported by models which include recent bereavements, although a descriptive comparison of risk among the working age band is suggestive of elevated risk to bereaved carers. However, analysis of caring intensity suggest that, among working age people, those bereaved after bearing the greatest caring burden were more at risk than non-bereaved carers. Therefore, there is no evidence of increased resilience accrued by bereaved carers ${ }^{7,8}$. The idea of deeper mourning, residual guilt ${ }^{6}$ or grief compounded by grief for one's own role, are substantiated but only among working age carers in the most intensive caring relationships. There is evidence that bereaved carers recover from mental ill-health at a different pace from other bereaved persons, although the direction of effect varies with age. Data on retirement age persons supports an easing of mental health burden with time for bereaved carers, whereas among working age persons, bereaved carers endure more sustained mental ill-health than those otherwise bereaved.

Hypothesis 2, that bereaved carers will be differently at risk of poor mental health compared to the rest of the caring population, is strongly supported in the case of working age carers, among whom a greater risk of mental health problems is estimated for bereaved than for nonbereaved carers. There is some support for the hypothesis in the case of older carers, but no 
evidence of a similar relationship among young carers. This challenges the idea of bereavement offering a reprieve from the burden of caring.

Hypothesis 3 is substantiated in so far as the excess risk to bereaved carers versus comparators was far greater for those who provided the greatest number of hours' care, supporting the proposition of Beery and colleagues ${ }^{9}$ that those with the greatest prior burden experience loss most acutely.

Results suggest that risks to carers, bereaved and otherwise, depend both on the length of time elapsed since bereavement and on the age of the carers. Older people appear to be more resilient to the stressful effects of unpaid caring and to experience less prolonged suffering after bereavement. Furthermore, while, for most adults, bereavement and caring burden appear to confer similar risks to mental health, the exception to this is people who provide care at a young age. Data for this group demonstrate that poor mental health outcomes are highly prevalent for carers of this age, more so than persons bereaved at a similar age. Only in the case of the retirement age band is there evidence of additional mental health risk to bereaved over non-bereaved carers.

The variation in how bereavement and caring experience interact to differently affect people at different life stages is intriguing. These differences allow for consideration underlying the risks to certain carers. The prolonged risk to people of working age could reflect disruption to normal working life, employability and attendant social support networks, contributing to longer-term mental health problems. It may also be that, for older people, being capable of caring for a dying relative is a marker of self-efficacy and self-worth which protects against some of the impact of witnessing that relative's health deteriorate and recalling that deterioration after death. Common to both of these putative mechanisms is the idea of role expectation. For working age people, a term of caring followed by bereavement may mark a 
departure from normative roles such as work and leisure, an incongruity between self-image and reality, and a resultant detachment from one's role within a social network. The lack of similar peers on whom to model one's own role may compound this. Meanwhile, caring is a more expected role among older people and inability to fulfil that role is the greater stressor.

\section{Limitations}

For the above interpretation of the observed trends, it is assumed that the distribution of antidepressant prescription accurately represents the distribution of mental health problems in the population. However, these trends may partly capture the judgement and attitude of physicians rather than latent mental ill-health. Some physicians may classify either caring burden or bereavement itself as a depressive symptom, signalling need for treatment and prescription. Even if antidepressant prescription is representative of underlying populationlevel mental health, physician prescribing captures only a subset of mental health problems. Therefore, the estimates provided of the effect of bereavement on likelihood of mental health problems are likely to be underestimates of the actual effect. However, existing evidence indicates that there is considerable correspondence between diagnostic assessment and antidepressant prescription, suggesting it is an acceptable proxy indicator ${ }^{11,12}$. Furthermore, the comparative effect on different groups is the central focus of this paper and there is no $a$ priori case that carers would be differently likely to see a physician following bereavement.

\section{Conclusions}

Services designed to alleviate mental health risks, both to bereaved persons and to the general population, should consider any history of a caring relationship between the bereaved and the decedent, but also the life stage of the bereaved person. 


\section{References}

1. Hawton K. Complicated grief after bereavement. BMJ.British Medical Journal. 2007;334(7601):962.

2. Lobb EA, Kristjanson LJ, Aoun SM, Monterosso L, Halkett GK, Davies A. Predictors of complicated grief: A systematic review of empirical studies. Death Stud. 2010;34(8):673698.

3. Buyck J, Bonnaud S, Boumendil A, et al. Informal caregiving and self-reported mental and physical health: Results from the GAZEL Cohort Study. American Journal of Public Health. 2011;101(10):1971-1979.

4. Hirst M. Carer distress: A prospective, population-based study. Soc Sci Med. 2005;61(3):697-708.

5. O'Reilly D, Connolly S, Rosato M, Patterson C. Is caring associated with an increased risk of mortality? A longitudinal study. Soc Sci Med. 2008;67(8):1282-1290.

6. Bodnar JC, Kiecolt-Glaser JK. Caregiver depression after bereavement: Chronic stress isn't over when it's over. Psychol Aging. 1994;9(3):372-380.

7. Schulz R, Boerner K, Shear K, Zhang S, Gitlin LN. Predictors of complicated grief among dementia caregivers: A prospective study of bereavement. The American Journal of Geriatric Psychiatry. 2006;14(8):650-658.

8. Chiu Y, Huang C, Yin S, Huang Y, Chien C, Chuang H. Determinants of complicated grief in caregivers who cared for terminal cancer patients. Supportive Care in Cancer. 2010;18(10):1321-1327. 
9. Beery LC, Prigerson HG, Bierhals AJ, et al. Traumatic grief, depression and caregiving in elderly spouses of the terminally ill. OMEGA--Journal of Death and Dying. 1997;35(3):261279.

10. Fujisawa D, Miyashita M, Nakajima S, Ito M, Kato M, Kim Y. Prevalence and determinants of complicated grief in general population. J Affect Disord. 2010;127(1):352358.

11. Henriksson S, Boëthius G, Håkansson J, Isacsson G. Indications for and outcome of antidepressant medication in a general population: A prescription database and medical record study, in Jämtland County, Sweden, 1995. Acta Psychiatr Scand. 2003;108(6):427431.

12. Gardarsdottir H, Heerdink E, Van Dijk L, Egberts A. Indications for antidepressant drug prescribing in general practice in the Netherlands. J Affect Disord. 2007;98(1):109-115. 
TABLE 1-Distribution of Characteristics Among Caregivers and Noncaregivers: Northern Ireland Longitudinal Study; Census Day 2001

\begin{tabular}{|c|c|c|c|c|c|c|c|c|}
\hline \multirow[t]{2}{*}{ Characteristic } & \multicolumn{2}{|c|}{ Combined Ages, N (\%) } & Young (16-24), N (\%) & \multicolumn{2}{|c|}{ Working Age (25-64), N (\%) } & \multicolumn{3}{|c|}{ Retirement Age ( $\geq 65), \mathrm{N}(\%)$} \\
\hline & Noncaregiver & Caregiver & Noncaregiver & Caregiver & Noncaregiver & Caregiver & Noncaregiver & Caregiver \\
\hline \multicolumn{9}{|l|}{ Hours unpaid care given: } \\
\hline $1-19 \mathrm{~h} / \mathrm{wk}$ & - & $25,339(59.07)$ & - & $1001(81.58)$ & - & $19,692(61.98)$ & - & $4646(46.93)$ \\
\hline $20-49$ h/wk & - & $6615(15.37)$ & - & $128(10.43)$ & - & $5031(15.84)$ & - & $1456(14.71)$ \\
\hline$\geq 50 \mathrm{~h} / \mathrm{wk}$ & - & $10,942(25.51)$ & - & $98(7.99)$ & - & $7046(22.18)$ & - & $3798(38.36)$ \\
\hline \multicolumn{9}{|l|}{ Gender } \\
\hline Female & $137,730(50.20)$ & $25,847(60.26)$ & $27,560(48.22)$ & 649 (52.89) & $87,252(50.56)$ & $19,453(61.23)$ & $22,918(51.13)$ & 5745 (58.03) \\
\hline Male & $136,638(49.80)$ & 17,049 (39.74) & $29,589(51.78)$ & $578(47.11)$ & $85,316(49.44)$ & $12,518(38.77)$ & $21,733(48.67)$ & 4155 (41.97) \\
\hline \multicolumn{9}{|l|}{ Religion } \\
\hline Protestant & $144,983(52.84)$ & $24,191(56.39)$ & $2,000(45.50)$ & $550(44.82)$ & $90,189(52.26)$ & $17,110(53.86)$ & $28,794(64.49)$ & $6531(65.97)$ \\
\hline Roman Catholic & $123,332(44.95)$ & $18,043(42.06)$ & $29,027(50.79)$ & $630(51.34)$ & 78,848 (45.69) & $14,140(44.51)$ & 15,457 (34.62) & 3273 (33.06) \\
\hline Other or no religion & $763(0.28)$ & $110(0.26)$ & $129(0.23)$ & $(<4.00 \%)^{a^{\prime}}$ & $534(0.31)$ & $86(0.26)$ & $100(0.22)$ & $(<1.00 \%)^{a}$ \\
\hline No response & $5290(1.93)$ & $552(1.29)$ & $1993(3.49)$ & $(<4.00 \%)^{\mathrm{a}}$ & $2997(1.74)$ & $435(1.37)$ & $300(0.67)$ & $(<1.00 \%)^{\mathrm{a}}$ \\
\hline \multicolumn{9}{|l|}{ General health } \\
\hline Good & $204,569(74.56)$ & $27,089(63.15)$ & $54,684(92.19)$ & $1052(85.74)$ & $131,450(76.17)$ & $21,373(67.28)$ & $20,435(45.77)$ & $4664(47.11)$ \\
\hline Fair & $46,687(17.02)$ & $11,934(27.82)$ & $3740(6.54)$ & $155(12.63)$ & $27,878(16.15)$ & $7988(25.14)$ & $15,069(33.75)$ & 3791 (38.29) \\
\hline Not good & $23,112(8.42)$ & 3873 (9.03) & $725(1.27)$ & $20(1.54)$ & $13,240(7.67)$ & 2408 (7.67) & $9147(20.90)$ & $1445(14.60)$ \\
\hline \multicolumn{9}{|l|}{ Long-term limiting illness } \\
\hline Yes & $44,381(16.18)$ & $8155(19.01)$ & $3503(6.09)$ & $89(7.31)$ & $22,662(13.03)$ & $4518(14.23)$ & $18,216(41.59)$ & 3548 (36.42) \\
\hline \multicolumn{9}{|l|}{ Accommodation type } \\
\hline $\begin{array}{l}\text { Detached house or } \\
\text { bungalow }\end{array}$ & $123,445(44.99)$ & $19,808(46.18)$ & $25,408(44.46)$ & $569(46.37)$ & $76,545(44.36)$ & $14,400(45.33)$ & $21,492(47.84)$ & $4839(48.13)$ \\
\hline $\begin{array}{l}\text { Semidetached house or } \\
\text { bunqalow }\end{array}$ & $77,909(28.40)$ & $11,855(27.64)$ & $15,869(27.77)$ & $314(25.59)$ & $50,333(29.17)$ & $8932(28.12)$ & $11,707(26.22)$ & $2609(26.35)$ \\
\hline Terraced & $67,250(24.51)$ & $10,363(24.16)$ & 15,079 (26.39) & $326(26.57)$ & $41,837(24.24)$ & $7819(24.61)$ & $10,334(23.14)$ & $2218(22.40)$ \\
\hline Other noncommunal & $5764(2.10)$ & $870(2.03)$ & $793(1.39)$ & $18(1.47)$ & $3853(2.23)$ & $618(1.95)$ & $1118(2.50)$ & $234(2.36)$ \\
\hline \multicolumn{9}{|l|}{ Car in household } \\
\hline No car & 35,869 (13.07) & $4883(11.38)$ & $9638(16.86)$ & $187(15.24)$ & 20,663 (11.97) & $3614(11.21)$ & $5568(12.47)$ & 1155 (11.67) \\
\hline 1 car & $114,328(41.67)$ & $18,387(42.86)$ & $25,003(43.75)$ & $546(44.50)$ & $66,761(38.69)$ & $13,030(40.40)$ & $22,564(50.63)$ & 4989 (50.39) \\
\hline$\geq, 2$ cars & $124,171(45.26)$ & $19,626(45.75)$ & $22,508(39.38)$ & $494(40.26)$ & $85,144(49.34)$ & $15,609(48.40)$ & $16,519(37.00)$ & 3756 (37.94) \\
\hline \multicolumn{9}{|l|}{ Household tenure/value } \\
\hline Renting & $55,977(20.40)$ & $8254(19.24)$ & $15,305(26.78)$ & $320(26.08)$ & $33,599(19.47)$ & $6413(20.19)$ & $7073(15.84)$ & $1521(15.36)$ \\
\hline Owner $/<£ 75,000$ & $27,386(9.98)$ & $3977(9.27)$ & $4703(8.23)$ & $110(8.96)$ & $17,059(9.89)$ & $2804(8.83)$ & $5624(12.60)$ & $1063(10.74)$ \\
\hline $\begin{array}{l}\text { Owner/£75,000- } \\
£ 159,999\end{array}$ & $110,936(40.43)$ & $17,572(40.96)$ & $20,702(36.22)$ & $450(36.67)$ & $70,947(41.11)$ & $12,861(40.48)$ & $19,287(43.20)$ & $4261(43.04)$ \\
\hline Owner $/ \geq £ 160,000$ & $52,131(19.00)$ & $9197(21.44)$ & $11,141(19.49)$ & $236(19.23)$ & 32,948 (19.09) & $6819(21.46)$ & $8042(18.01)$ & $2142(21.64)$ \\
\hline Missing & $27,938(10.18)$ & $3896(9.08)$ & $5298(9.27)$ & $111(9.05)$ & $18,015(10.44)$ & $2872(9.04)$ & $4625(10.36)$ & $913(9.22)$ \\
\hline \multicolumn{9}{|l|}{ Education $^{\mathrm{b}}$} \\
\hline No qualifications & $84,600(30.83)$ & $16,765(39.08)$ & - & - & $54,949(31.84)$ & $10,751(33.84)$ & $29,651(66.41)$ & $6014(60.75)$ \\
\hline
\end{tabular}




\begin{tabular}{|c|c|c|c|c|c|c|c|c|}
\hline \\
\hline Foundation & $39,607(14.44)$ & $7297(17.01)$ & - & - & $37,765(21.88)$ & $6722(21.16)$ & $1842(4.13)$ & $575(5.81)$ \\
\hline$\geq 5$ GCSE & $36,507(13.31)$ & 7057 (16.45) & - & - & $32,889(19.06)$ & $5940(18.70)$ & $3618(8.10)$ & $1117(11.28)$ \\
\hline A levels & $19,036(6.94)$ & $3100(7.23)$ & - & - & $18,289(10.60)$ & $2881(9.07)$ & $747(1.64)$ & $219(2.21)$ \\
\hline 1st degree & $32,394(11.81)$ & $6581(15.34)$ & - & - & $28,676(16.62)$ & $5475(17.23)$ & 3718 (8.33) & $1106(11.17)$ \\
\hline Not asked $(\geq 74)$ & $62224(22.68)$ & $2096(4.89)$ & - & - & - & - & 5075 (11.37) & $869(8.78)$ \\
\hline \multicolumn{9}{|l|}{ Income deprivation quintile } \\
\hline 1 & $51,766(18.87)$ & $8810(20.54)$ & $9,770(17.10)$ & $199(16.22)$ & $32,896(19.06)$ & $6297(19.82)$ & $9100(20.38)$ & 2363 (23.37) \\
\hline 2 & $54,513(19.87)$ & $8386(19.55)$ & $10,737(18.79)$ & $217(17.69)$ & $34,905(20.23)$ & $6255(19.69)$ & $8871(19.87)$ & $1914(19.33)$ \\
\hline 3 & $52,748(19.23)$ & $8001(18.65)$ & $10,648(18.63)$ & $244(19.89)$ & $33,534(19.43)$ & $5851(18.42)$ & $8566(19.18)$ & $1906(19.25)$ \\
\hline 4 & $51,946(18.93)$ & $7788(18.16)$ & $10,894(19.06)$ & $240(19.56)$ & $32,537(18.85)$ & $5785(18.21)$ & 8515 (19.07) & $1763(17.81)$ \\
\hline 5 & $49,028(17.87)$ & $7814(18.22)$ & $12,340(21.59)$ & $272(22.17)$ & $29,761(17.25)$ & $6046(19.03)$ & $6927(15.51)$ & $1496(15.11)$ \\
\hline Missing & $14,367(5.24)$ & $2097(4.89)$ & $2760(4.83)$ & $55(4.48)$ & $8935(5.18)$ & $1535(4.83)$ & $2672(5.98)$ & $507(5.12)$ \\
\hline \multicolumn{9}{|l|}{ Family structure } \\
\hline \multirow{2}{*}{$\begin{array}{l}\text { U16: } 2 \text { biological parents } \\
\text { U16: Single biological }\end{array}$} & $39,872(14.53)$ & $845(1.97)$ & $39,872(69.77)$ & $845(68.87)$ & - & - & - & - \\
\hline & $14,136(5.15)$ & $323(0.75)$ & $14,136(24.74)$ & $323(26.32)$ & - & - & - & - \\
\hline $\begin{array}{l}\text { U16: Step- or } \\
\text { reconstituted family }\end{array}$ & $1268(0.46)$ & $25(0.06)$ & $1268(2.22)$ & $25(2.04)$ & - & - & - & - \\
\hline $\begin{array}{l}\text { U16: Alternative } \\
\text { household }\end{array}$ & $1873(0.68)$ & $34(0.08)$ & $1873(3.28)$ & $34(2.77)$ & - & - & - & - \\
\hline $\begin{array}{l}\text { Parent(s) only_single } \\
\text { Parent(s) only_- }\end{array}$ & $49,080(17.89)$ & $5079(11.84)$ & - & - & $48,897(28.33)$ & $4866(15.32)$ & $183(0.41)$ & $213(2.15)$ \\
\hline $\begin{array}{l}\text { widowed, separated, } \\
\text { divorced }\end{array}$ & $1013(0.37)$ & $313(0.73)$ & - & - & $977(0.57)$ & $253(0.80)$ & $36(0.08)$ & $60(0.61)$ \\
\hline \multirow{2}{*}{$\begin{array}{l}\text { Partner only } \\
\text { Kids only - single }\end{array}$} & $45,749(16.67)$ & $9010(21.00)$ & - & - & $21,789(12.63)$ & 3814 (12.01) & $23,960(53.66)$ & $5196(52.48)$ \\
\hline & $4651(1.70)$ & $836(1.95)$ & - & - & $4489(2.60)$ & 817 (2.57) & $162(0.36)$ & $19(0.19)$ \\
\hline $\begin{array}{l}\text { Kids only-widowed, } \\
\text { separated, divorced }\end{array}$ & $12,700(4.63)$ & 2406 (5.61) & - & - & $8382(4.86)$ & 1870 (5.89) & $4318(9.67)$ & $536(5.41)$ \\
\hline \multirow{2}{*}{$\begin{array}{l}\text { Partner \& kids only } \\
\text { Alternative household- }\end{array}$} & 93,194 (33.97) & $21,879(51.00)$ & - & - & $79,739(46.21)$ & $18,513(58.27)$ & $13,455(30.13)$ & $3366(34.00)$ \\
\hline & 8019 (2.92) & $974(2.27)$ & - & - & $6271(3.63)$ & $719(2.26)$ & 1748 (3.91) & $255(2.58)$ \\
\hline $\begin{array}{l}\text { Alternative household- } \\
\text { married or cohabiting } \\
\text { Alternative household- }\end{array}$ & $1409(0.51)$ & $886(2.07)$ & - & - & $1223(0.71)$ & 717 (2.26) & $186(0.42)$ & $169(1.71)$ \\
\hline $\begin{array}{l}\text { widowed, separated, } \\
\text { divorced }\end{array}$ & $1404(0.51)$ & $286(0.67)$ & - & - & $801(0.46)$ & $200(0.62)$ & $603(1.35)$ & $86(0.87)$ \\
\hline
\end{tabular}

Note. GCSE=General Certificate of Secondary Education; U16=under 16. Dashes indicate not applicable.

${ }^{a}$ Numbers obscured to conform to Northern Ireland Statistics and Research Agency disclosure policy.

${ }^{b}$ Education variable only available for cohort members aged older than 16 y at Census 2001. 
TABLE 2-Descriptive Distribution of Mental Health-Related Prescriptions by Caregiver Status: Northern Ireland Longitudinal Study; January-February 2010

\begin{tabular}{|c|c|c|c|c|c|c|}
\hline \multirow[t]{2}{*}{ Status } & \multirow[t]{2}{*}{ Total No. } & \multirow[b]{2}{*}{$\begin{array}{c}\text { Poor Mental } \\
\text { Health } \\
\text { (Prescribed } \\
\text { Antidepressant), } \\
\mathrm{N}(\%) \\
\end{array}$} & \multicolumn{4}{|c|}{ Unadjusted ORs (95\% Cl) } \\
\hline & & & $\begin{array}{l}\text { Combined } \\
\text { Ages }\end{array}$ & $\begin{array}{c}\text { Young (16- } \\
24)\end{array}$ & $\begin{array}{c}\text { Working } \\
\text { Age (25-64) }\end{array}$ & $\begin{array}{l}\text { Retirement } \\
\text { Age }(\geq 65)\end{array}$ \\
\hline $\begin{array}{l}\text { Caregiver: } \\
\quad \text { Bereaved }\end{array}$ & 5414 & $850(15.70)$ & $\begin{array}{c}1.82^{*} \\
(1.68,1.97)\end{array}$ & $\begin{array}{c}0.91 \\
(0.23,3.67)\end{array}$ & $\begin{array}{c}1.56^{*} \\
(1.41,1.72)\end{array}$ & $\begin{array}{c}1.44^{*} \\
(1.28,1.63)\end{array}$ \\
\hline Nonbereaved & 18,690 & 2789 (14.92) & $\begin{array}{c}1.72^{*} \\
(1.64,1.79)\end{array}$ & $\begin{array}{c}2.65^{\star} \\
(2.03,3.46)\end{array}$ & $\begin{array}{c}1.56^{*} \\
(1.48,1.64)\end{array}$ & $\begin{array}{c}1.17^{*} \\
(1.07,1.28)\end{array}$ \\
\hline $\begin{array}{r}\text { Noncaregiver: } \\
\text { Bereaved }\end{array}$ & 18,407 & $2423(13.16)$ & $\begin{array}{c}1.48^{*} \\
(1.41,1.56)\end{array}$ & $\begin{array}{c}1.59^{*} \\
(1.26,2.00)\end{array}$ & $\begin{array}{c}1.16^{*} \\
(1.09,1.25)\end{array}$ & $\begin{array}{c}1.60^{*} \\
(1.48,1.73)\end{array}$ \\
\hline $\begin{array}{l}\text { Nonbereaved } \\
\text { noncaregivers } \\
\text { (Ref.) }\end{array}$ & 274,753 & $25,475(9.27)$ & 1.00 & 1.00 & 1.00 & 1.00 \\
\hline
\end{tabular}

Note. $\mathrm{Cl}=$ confidence interval; $\mathrm{OR}=$ odds ratio. Reference group is nonbereaved noncaregivers.

${ }^{\star} P<.05$.

TABLE 3-Covariate-Adjusted Odds Ratios for Poor Mental Health by Bereavement and

Caregiver Status: Northern Ireland Longitudinal Study; January-February 2010

\begin{tabular}{|c|c|c|c|}
\hline Status & $\begin{array}{c}\text { Young Age (16-24), } \\
\text { OR }(95 \% \mathrm{Cl})\end{array}$ & $\begin{array}{c}\text { Working Age (25-64), } \\
\text { OR }(95 \% \mathrm{Cl})\end{array}$ & $\begin{array}{c}\text { Retirement Age }(\geq 65) \text {, } \\
\text { OR }(95 \% \mathrm{Cl})\end{array}$ \\
\hline \multicolumn{4}{|l|}{ Caregiver } \\
\hline Nonbereaved & $2.42^{*}(1.82,3.21)$ & $1.17^{*}(1.11,1.24)$ & $1.11^{*}(1.01,1.29)$ \\
\hline Bereaved, 2001-2009 & $1.00(0.25,3.20)$ & $1.41^{*}(1.27,1.57)$ & $1.38^{*}(1.21,1.56)$ \\
\hline Bereaved, 2007-2009 & $3.42(0.80,14.56)$ & $1.52^{*}(1.25,1.84)$ & $1.60 *(1.29,1.97)$ \\
\hline Bereaved, 2005-2006 & - & $1.26^{*}(1.02,1.57)$ & $1.49 *(1.19,1.98)$ \\
\hline \multirow[t]{2}{*}{ Bereaved 2001-2004 } & - & $1.39 *(1.19,1.62)$ & \\
\hline & & & $1.20(1.00,1.43)$ \\
\hline \multicolumn{4}{|l|}{ Noncaregiver } \\
\hline Bereaved 2001-2009 & $1.45^{\star}(1.14,1.86)$ & $1.24^{*}(1.15,1.33)$ & $1.42^{*}(1.30,1.54)$ \\
\hline Bereaved 2007-2009 & $1.52^{*}(1.04,2.22)$ & $1.23^{*}(1.11,1.38)$ & $1.48(1.32,1.66)$ \\
\hline Bereaved 2005-2006 & $1.19(0.73,1.93)$ & $1.40 *(1.24,1.59)$ & $1.49^{*}(1.29,1.71)$ \\
\hline Bereaved 2001-2004 & $1.55(1.11,2.17)$ & $1.14(1.01,1.28)$ & $1.31^{*}(1.15,1.48)$ \\
\hline
\end{tabular}

Note. $\mathrm{Cl}=$ confidence interval; $\mathrm{OR}=$ odds ratio. Reference group is nonbereaved noncaregivers. Logistic regressions adjust for sex, age, religion, economic activity, deprivation, physical health, household structure and housing. Dashes indicate numbers not sufficient to estimate.

${ }^{*} P<.05$. 
TABLE 4-Covariate-Adjusted Odds Ratios for Mental Ill Health by Bereavement Status and Caring Burden: Northern Ireland Longitudinal Study; January-February 2010

\begin{tabular}{lccccc}
\hline \multicolumn{1}{c}{ Status } & No. & $\begin{array}{c}\text { Total } \\
\text { Antid }\end{array}$ & $\begin{array}{c}\text { Young Age (16-24), } \\
\text { OR }(95 \% \mathrm{Cl})\end{array}$ & $\begin{array}{c}\text { Working Age (25-64), } \\
\text { OR }(95 \% \mathrm{Cl})\end{array}$ & $\begin{array}{c}\text { Retirement Age }(\geq 65), \\
\text { OR }(95 \% \mathrm{Cl})\end{array}$ \\
\hline $\begin{array}{l}\text { Bereaved caregiver } \\
\quad \text { 20 h }\end{array}$ & 1564 & 188 & $1.19(0.29,4.79)$ & $1.32^{*}(1.09,1.62)$ & $1.33^{*}(1.03,1.75)$ \\
$\quad$ 20-49 h & 1002 & 145 & - & $1.23(0.98,1.56)$ & $1.43^{*}(1.05,1.96)$ \\
$\quad>50 \mathrm{~h}$ & 2848 & 517 & - & $1.54^{*}(1.33,1.78)$ & $1.37^{*}(1.19,1.58)$ \\
$\begin{array}{l}\text { Nonbereaved caregiver } \\
\quad \text { 20 h }\end{array}$ & 7969 & 918 & $2.68^{*}(1.94,3.70)$ & $1.14^{*}(1.05-1.23)$ & $1.10(0.93,1.31)$ \\
$\quad$ 20-49 h & 3477 & 554 & $2.50^{*}(1.24,5.02)$ & $1.23^{*}(1.10,1.38)$ & $1.14(0.94,1.39)$ \\
$\quad>50 \mathrm{~h}$ & 7244 & 1317 & $0.84(0.20,3.58)$ & $1.19^{*}(1.10,1.28)$ & $1.10(0.96,1.26)$ \\
Bereaved noncaregiver & 18,407 & 2423 & $1.47^{*}(1.15,1.88)$ & $1.24^{*}(1.15,1.33)$ & $1.42^{*}(1.30,1.54)$ \\
\hline
\end{tabular}

Note. Antid=antidepressant; $\mathrm{Cl}=$ confidence interval; $\mathrm{OR}=$ odds ratio. Reference group is nonbereaved noncaregivers. Dashes indicate numbers not sufficient to estimate.

${ }^{\star} P<.05$. 